\title{
The effects of progressive low to high intensity exercise training on blood lipids and lipoprotein profiles in collegiate adolescents
}

\author{
Biruk Amare SORATE ${ }^{1}$
}

${ }^{1}$ Department of Sport Sciences, Jimma University, Jimma, Ethiopia.

Address correspondence to B. A. Sorate, e-mail: amarebruk@gmail.com

\begin{abstract}
The purpose of this study was to examine the effects of progressive low to high intensity exercise training on blood lipids and lipoprotein profiles in collegiate adolescents. Twenty (20) male and female adolescents who were volunteer to participate in physical exercise program and who were studying in Jimma University College of natural science were taken as a subject. The selected subjects were evaluated the baseline blood lipids and lipoprotein profiles before starting exercise training. Registered laboratory technicians were collect a sample of $5 \mathrm{~mL}$ fasting venous blood from each subject just before beginning the exercise, the second and the third blood tests were performed after the $4^{\text {th }}$ and $8^{\text {th }}$ weeks exercise training programs respectively. The subjects assigned to an individualized training program that consisted of walking, jogging and running progressively from low to high intensity. During 8 weeks the program included three training sessions per week. Descriptive statistics were produced for each of the parameters. Paired sample T-tests was performed, to find out the significant difference in selected lipid and lipoprotein profile. The significance level was set at $\mathrm{P}<0.05$ for each of the statistical tests performed. The SPSS 20 software was used for the statistical analysis. The mean TC difference of male and female subjects was $39.160 \mathrm{mmol} / \mathrm{L}(26.61 \%)$ and $50.260 \mathrm{mmol} / \mathrm{L}(29.63 \%)$ respectively after exercise training. The mean TG difference of male and female subjects was $20.660 \mathrm{mmol} / \mathrm{L}(19.31 \%)$ and by $23.020 \mathrm{mmol} / \mathrm{L}(18.68 \%)$ respectively after exercise training. The mean HDL difference of male and female subjects was $28.630 \mathrm{mmol} / \mathrm{L}(58.29 \%)$ and $24.320 \mathrm{mmol} / \mathrm{L}(52.04 \%)$ respectively after exercise training. And the mean LDL difference of male and female subjects was $33.080 \mathrm{mmol} / \mathrm{L}(31.03 \%)$ and by $48.210 \mathrm{mmol} / \mathrm{L}(36.58 \%)$ respectively after exercise training. Both male and female subjects showed that a significant increment in HDL and significant decrements showed in TC and LDL but not in TG. This study showed that exercise in female subjects reduce better TC, TG and LDL level than male subjects and male subjects develop better HDL level than female subjects. To be more beneficial in blood lipids and lipoprotein changes adolescents should participate in progressive low to high intensity exercise training programs additional to their daily routine.
\end{abstract}

Key words: Body weight, BMI, blood cholesterol, triglyceride, LDL, and HDL.

\section{INTRODUCTION}

A consensus exists that physical inactivity and reduced cardio respiratory endurance contribute to risk of coronary heart disease (CHD) (13). Among the multiple proposed mechanisms for the postulated protective effect of regular physical activity against CHD is a favorable effect on blood lipids, particularly an increase in high-density lipoprotein cholesterol (HDL-C) and a reduction in triglyceride (TG) levels (19).

Exercise, primarily aerobic exercise, is a low-cost therapeutic lifestyle change that has been recommended for improving lipid and lipoprotein levels in adults (14). While previous meta-analytic research has reported significant improvements in lipids and lipoproteins among both men (7) and women (6) as a result of aerobic exercise on lipids and lipoproteins in adults have been underwhelming.

Lipoprotein levels are directly related to the process of atherosclerosis and therefore to the occurrence of CHD. Although total serum cholesterol has been found to be related to $\mathrm{CHD}$, its atherogenic effect depends on the structure of the cholesterol or, in other words, on the ratio between low-density lipoprotein cholesterol (LDL) and high-density 
lipoprotein cholesterol (HDL). It is assumed that LDL may act directly or indirectly to cause endothelial damage, with subsequent proliferation of arterial smooth muscle cells resulting in an accumulation of lipids and a progression to atherosclerotic plaque formation. HDL, on the other hand, is assumed to be protective against CHD; HDL seems to be responsible for carrying cholesterol from peripheral tissue, including the arterial walls, back to the liver where it is metabolized and excreted (10)

Besides HDL and LDL, very low-density lipoprotein cholesterol (VLDL) and plasma triglycerides (TG) also need to be considered. Although the atherogenic effects of VLDL and TG are not firmly established, both are assumed to be risk factors for CHD. It is further assumed that during exercise, fatty acids are freed from their storage sites to be burned for energy production (10).

Physical activity can improve quality of life and is a critical component in reducing or eliminating health disparities through lowering resting heart rate and blood pressure, reducing hypertension, reducing blood glucose, decreasing fat body mass and increasing lean body mass, increasing bone mass and bone strength, increasing muscle strength, preventing arthritis, and reducing symptoms of mild or moderate depression. Rates of leisure-time physical activity, however, are lowest among women, ethnic minorities, and persons of low socioeconomic status, older adults, and persons living in rural settings $(5,15)$.

Several of the studies have investigated the effects of combined exercise and diet on lipids and lipoproteins but few have looked at the effects of physical exercise alone $(2,18)$. Physical exercise has long been acknowledged as an important part of a healthy lifestyle, and recent scientific evidence has linked regular physical exercise to a wide range of physical health benefits. Research has demonstrated protective effects of varying strength between physical exercise and risk for several chronic diseases, including coronary heart disease, hypertension, noninsulin dependent diabetes mellitus, osteoporosis, and colon cancer (18).

In our country Ethiopia, because of sedentary life style most people are attacked by chronic disease such as; coronary heart disease, hypertension, diabetes, and the like. This is caused by lack of awareness and their attitude towards the benefits of physical exercise for their health. Similarly, in Jimma University students are living sedentary lifestyle due to poor culture of having regular physical exercise.

Thus, the researcher hypothesized that; progressive low to high intensity exercise training could have a positive effects on blood lipids and lipoprotein profiles in collegiate adolescents. Therefore, the purpose of this study was to examine the effects of progressive low to high intensity exercise training on blood lipids and lipoprotein profiles in collegiate adolescents.

\section{MATERIAL \& METHOD}

\section{Study Design and Area}

The researcher was used longitudinal experimental research design because participants are tested than one test and trained for 8 weeks from October 1, 2013 to November 30, 2013. The study was conducted in Jimma town of Jimma University main campus, located $350 \mathrm{~km}$ in south-west of Addis Ababa.

\section{Subjects}

Twenty subjects (10 male and 10 female adolescents) who were volunteer to participate in progressive low to high intensity physical exercise program and who were studying in Jimma University College of natural science were taken as a subject. Then after, the selected subjects were evaluated the baseline blood lipids and lipoprotein profiles before starting exercise training.

Participants were free of risk factors associated with cardiovascular, pulmonary or metabolic disease, deemed safe to begin physical activity, and were not engaged in other regular training program. Other exclusion criteria included medication usage and smoking. The experimental procedures and potential risks were explained prior to the study, and all participants signed written, informed consent.

\section{Intervention (training) program}

The subjects assigned to the exercise were given an individualized training program that consisted of walking, jogging, and running progressively from low to high intensity. During 8 weeks the program included three weekly training sessions at an intensity that was adjusted to get the previously non active participants accustomed to physical exercise. The subjects were instructed to determine their training 
heart rates from $10 \mathrm{~s}$ pulse counts estimated several times during the exercise. The participants were advised to have a warm-up period of 15 min before and a $10 \mathrm{~min}$ slow-down period after the $30 \mathrm{~min}$ exercise period to avoid the risks of too-vigorous changes of physical activity.

\section{Blood Test}

Registered laboratory technicians drew a sample of $5 \mathrm{~mL}$ fasting venous blood from each subject just before beginning the exercise, the second and the third blood tests were performed after the $4^{\text {th }}$ and $8^{\text {th }}$ weeks exercise training programs respectively. The blood samples were collected under fasting conditions between 7:30 and 9:00 am. The values from the first test were used as the baseline for the parameters. In the EDTA samples, the following variables were analyzed by humalyzer 3000 blood chemistry analyzer: Total cholesterol (TC), Low density lipoprotein (LDL), High density lipoprotein (HDL) and Triglyceride (TG). The tests were strictly measured and recorded by the researcher and certified laboratory technician of Jimma University specialized hospital. Blood chemistry parameters were classified as abnormal based on standard reference values.

Total cholesterol (TC) test: Total cholesterol in blood was measured. The total blood cholesterol measures all types of cholesterol, low density lipoprotein, high density lipoprotein and triglyceride altogether. The normal value of total cholesterol Desirable: $<5.2$ $\mathrm{mmol} / \mathrm{L}$, Borderline high: 5.2-6.2 $\mathrm{mmol} / \mathrm{L}$ and High: $>6.2 \mathrm{mmol} / \mathrm{L}$. (20).

Low density lipoprotein (LDL) test: The amount of low density lipoprotein was measured. As LDL levels increase, the cholesterol accumulates along the walls of the arteries, which increase the risk of heart disease. Therefore, this test was performed to see if LDL is low enough. The normal value of LDL Desirable: $<3.4$ mmol/L, Borderline: $3.4-4.1 \mathrm{mmol} / \mathrm{L}$ and High: $>4.1$ $\mathrm{mmol} / \mathrm{L}(20)$.

Table 1. Characteristics of the study subjects (Mean \pm SD).

\begin{tabular}{lcccccc}
\hline & \multicolumn{3}{c}{ Male } & & \multicolumn{2}{c}{ Female } \\
\hline & PT & DT & PoT & PT & DT & PoT \\
Age (years) & $18.2 \pm 0.789$ & $18.2 \pm 0.789$ & $18.2 \pm 0.789$ & $18.1 \pm 0.738$ & $18.1 \pm 0.738$ & $18.1 \pm 0.738$ \\
Height $(\mathrm{m})$ & $1.70 \pm 0.03$ & $1.70 \pm 0.03$ & $1.70 \pm 0.03$ & $1.59 \pm 0.06$ & $1.59 \pm 0.06$ & $1.59 \pm 0.06$ \\
Weight $(\mathrm{Kg})$ & $61.4 \pm 4.76$ & $59.0 \pm 4.39$ & $58.0 \pm 3.91$ & $56.5 \pm 6.89$ & $54.5 \pm 7.32$ & $52.8 \pm 6.72$ \\
BMI $\left(\mathrm{Kg} / \mathrm{m}^{2}\right)$ & $21.2 \pm 2.34$ & $20.4 \pm 2.23$ & $20.0 \pm 2.03$ & $22.4 \pm 2.86$ & $21.6 \pm 3.02$ & $20.9 \pm 2.76$ \\
& & & & & & \\
\hline
\end{tabular}

Mean \pm SD in the same columns in each parameter are not significantly different $(\mathrm{p}<0.05), \mathrm{BMI}\left(\mathrm{kg} / \mathrm{m}^{2}\right)=$ Body mass index.
High density lipoprotein (HDL) test: This test provided result for the level of high density lipoprotein in the blood. It was performed to determine if HDL is high enough. The normal value of HDL Men: Desirable $>0.9 \mathrm{mmol} / \mathrm{L}$, Low: $<0.9$ $\mathrm{mmol} / \mathrm{L}$ and Women: Desirable $>1.42 \mathrm{mmol} / \mathrm{L}$ (20).

Triglyceride (TG) test: This test measures the amount of triglycerides in blood. It was used to diagnose and monitor disorders of lipids (fat) in blood and to help determine the risk of developing heart disease. The normal value of triglyceride Desirable: $<2.3 \mathrm{mmol} / \mathrm{L}$, Borderline high: 2.3-4.5 mmol/L, High: 4.5-11.3 $\mathrm{mmol} / \mathrm{L}$ and Very high: $>11.3 \mathrm{mmol} / \mathrm{L}$ (20).

\section{Data Analysis}

Descriptive statistics were produced for each of the parameters. Paired sample T-tests was performed, to find out the significant difference in selected lipid and lipoprotein profile. The significance level was set at $\mathrm{P}<0.05$ for each of the statistical tests performed. The SPSS 20 software was used for the statistical analysis.

\section{RESULTS \& DISCUSSION}

The mean TC difference of male and female subjects was $39.160 \mathrm{mmol} / \mathrm{L}$ (26.61\%) and 50.260 $\mathrm{mmol} / \mathrm{L}(29.63 \%)$ respectively after exercise training. The mean TG difference of male and female subjects was $20.660 \mathrm{mmol} / \mathrm{L}(19.31 \%)$ and by $23.020 \mathrm{mmol} / \mathrm{L}$ $(18.68 \%)$ respectively after exercise training. The mean HDL difference of male and female subjects was $28.630 \mathrm{mmol} / \mathrm{L}(58.29 \%)$ and $24.320 \mathrm{mmol} / \mathrm{L}(52.04 \%)$ respectively after exercise training. And the mean LDL difference of male and female subjects was $33.080 \mathrm{mmol} / \mathrm{L}(31.03 \%)$ and by $48.210 \mathrm{mmol} / \mathrm{L}$ $(36.58 \%)$ respectively after exercise training. Both male and female subjects showed that a significant increment in HDL and significant decrements showed in TC and LDL but not in TG. 
Table 2. Mean effects of blood chemistry tests.

\begin{tabular}{|c|c|c|c|c|c|c|c|c|}
\hline \multicolumn{5}{|c|}{ Male } & \multicolumn{4}{|c|}{ Female } \\
\hline Treatments & $\mathrm{TC}$ & TG & HDL & LDL & TC & TG & HDL & LDL \\
\hline PT & $\begin{array}{c}147.15 \pm \\
37.91\end{array}$ & $\begin{array}{c}106.98 \pm \\
56.07\end{array}$ & $\begin{array}{c}49.11 \pm \\
5.75\end{array}$ & $\begin{array}{c}106.60 \pm \\
26.55\end{array}$ & $\begin{array}{c}169.60 \pm \\
52.96\end{array}$ & $\begin{array}{c}123.18 \pm \\
40.72\end{array}$ & $\begin{array}{c}46.73 \pm \\
4.16\end{array}$ & $\begin{array}{c}131.76 \pm \\
25.50\end{array}$ \\
\hline PoT & $\begin{array}{c}107.99 \pm \\
22.28\end{array}$ & $86.32 \pm 34.76$ & $\begin{array}{c}77.74 \pm \\
12.35\end{array}$ & $\begin{array}{c}73.52 \pm \\
12.81\end{array}$ & $\begin{array}{c}119.34 \pm \\
35.93\end{array}$ & $\begin{array}{c}100.16 \pm \\
22.36\end{array}$ & $\begin{array}{c}71.05 \pm \\
5.44\end{array}$ & $83.55 \pm 12.34$ \\
\hline Mean Diff. & $39.160^{*}$ & 20.660 & $-28.630^{*}$ & $33.080^{*}$ & $50.260^{*}$ & 23.020 & $-24.320^{*}$ & $48.210^{*}$ \\
\hline Sig. & 0.006 & 0.349 & 0.000 & 0.001 & 0.016 & 0.148 & 0.000 & 0.000 \\
\hline
\end{tabular}

The most frequently observed change is an increase in HDL. It is estimated that for every 0.026 $\mathrm{mmol} / \mathrm{L}(1 \mathrm{mg} / \mathrm{dL})$ increase in HDL, the risk for a coronary heart disease event is reduced by $2 \%$ in men and at least $3 \%$ in women $(11,12)$. There are plenty studies indicating that regular exercises increases HDL. Şekeroğlu et al. (16) has observed decrease in the level of serum triglyceride and increase in HDL after 5-week exercise program. Reduction in TC, LDL, and TG also may occur with training. In general, a $1 \%$ reduction in LDL is associated with a $2-3 \%$ lower risk of coronary heart disease (9). Exercise training also appears to attenuate the reduction in HDL accompanying a decreased dietary intake of saturated fat and cholesterol to promote reduction of LDL. Bedir et al. (1) have found that young female doing sports have lower level of total cholesterol and higher HDL-C and LDL-C than sedentary young females. Earlier reviewers noted a trend for a lower prevalence of training induced increase in HDL levels in women $(3,4,8,17)$. However, the results of this study showed that sex is not a predictor of responsiveness of HDL to training, with adolescent men and women appearing to respond similarly.

Both male and female subjects reduce better TC, TG and LDL level develop better HDL level. Exercise is necessary to reduce TC, TG and LDL concentration. Progressively from low to high intensity exercise is necessary for controlling the normal range of blood lipids and lipoprotein.

By considering the major findings and conclusions of the study, it is important to state the following points as a recommendation to investigate more on effects of exercise training on blood lipids and lipoprotein profiles in collegiate adolescents. It is highly expected from sport professionals and related fields to guide and educate on the importance and value of exercise on balancing blood lipids and lipoprotein changes. To be more beneficial in blood lipids and lipoprotein changes adolescents should participate in exercise training programs additional to their daily routine. Further research has to be done on the role of exercise training programs for the improvement of adolescents' blood lipids and lipoprotein changes.

\section{REFERENCES}

1. Bedir A, Adam B, Imamoglu O, Kuru Ö. The effect of exercise training on lipid profile in Turkish young adults. The New Sports of Medicine, 1998; 15(1): 4.

2. Crouse SF, O'Brien BC, Grandjean PW, Lowe RC, Rohack JJ, Green JS. Effects of training and a single session of exercise on lipids and Apo lipoproteins in hypercholesterolemia men. J Appl Physiol, 1997; 83: 2019-28.

3. Durstine JL, HASKELL WL. Effects of exercise training on plasma lipids and lipoproteins. Exerc Sports Sci Rev, 1994; 22: 477-521.

4. Goldberg L, Elliot DL. The effects of exercise on lipid metabolism in men and women. Sports Med, 1987; 4: 307-321.

5. Jones DA, Ainsworth BE, Croft JB, Macera CA, Lloyd EE, Yusuf HR. Moderate leisure time physical activity: who is meeting the public health recommendations? A national cross-sectional study. Archives of Family Medicine, 1998; 7: 285-289.

6. Kelley GA, Kelley KS, Tran ZV. Aerobic exercise and lipids and lipoproteins in women: a meta-analysis of randomized controlled trials. J Women's Health, 2004; 13: 1148-1164.

7. Kelley GA, Kelley KS. Aerobic exercise and lipids and lipoproteins in men: a meta-analysis of randomized controlled trials. J Mens Health Gend, 2006; 3: 61-70.

8. Leon AS. Effects of exercise conditioning on physiologic precursors of CHD. J Cardiopulm Rehabil, 1991; 11: 46 -57.

9. National Cholesterol Education Program. Second Report of the Expert Panel on Detection, Evaluation, and Treatment of High Blood Cholesterol in Adults. Bethesda, MD: NIH Publication No. 93-3095: September 1993, I-1-14, IV-6 - 8.

10. Neil A. Paediatric Exercise Physiology. Elsevier Limited. Philadelphia, USA 1sted; 2007: 331p. 
11. Nicklas BJ, Katzel LI, Busby-Whitehead J, Goldberg AP. Increases in high-density lipoprotein cholesterol with endurance exercise training are blunted in obese compared with lean men. Metabolism, 46:556 -561.

12. Pasternak RC, Grundy SM, Levy D, Thompson PD. (1990) Spectrum of risk factors for CHD. J Am Coll Cardiol, 1990; 27: $964-1047$.

13. Pate RR, Pratt M, Blair SN. Physical activity and public health. Are commendation for the Centers for Disease Control and Prevention and the American College of Sports Medicine. JAMA, 1995; 273: 402- 407.

14. Rosamond W, Flegal K, Furie K. Heart disease and stroke statistics-2008 update: a report from the American Heart Association Statistics Committee and Stroke Statistics Subcommittee. Circulation, 2008; 117: 25-146.

15. Sallis JF, Owen N. Determinants of physical activity, In Physical activity and behavioral medicine. 1999: 110-134.

16. Sekeroglu RM, Aslan R, Tarakçioglu M, Kara M. Sedanter erkeklerde akut ve programlı egzersizin serum apolipoproteinleri ve lipitleri üzerine etkileri. Genel Tıp Dergisi, 1997; 7(1): 5-8.

17. Stefanick ML, Wood PD. Physical activity, lipid and lipid transport. In: Physical Activity, Fitness, and Health. International. Proceedings and Consensus Statement. C. Bouchard, RJ Shephard, and T. Stephens (Eds.). Champaign, IL: Human Kinetics, 1994: 417- 431.

18. Tall A. Exercise to reduce cardiovascular risk: how much is enough? England Journal of Medicine, 2002; 347: 1522-25.

19. US Department of Health and Human Services. Physical Activity and Health: a Report of the Surgeon General. Atlanta, GA: U.S. Department of Health and Human Services, Centers for Disease Control and Prevention, National Center for Chronic Disease Prevention and Health Promotion, 1996: 1-278.

20. Williams MH. Nutrition: For Health, Fitness and sport (6th Ed.). London: McGraw-Hill, 2002. 